\title{
Comparison of efficacy and safety of injectable iron sucrose with oral ferrous ascorbate in the treatment of anaemia in pregnancy
}

\author{
Sunitha H. B. ${ }^{1 *}$, Sunil Kumar G. S. $^{2}$
}

\begin{abstract}
${ }^{1}$ Department of Obstetrics and Gynecology, Gadag Institute of Medical Sciences, Gadag, Karnataka, India ${ }^{2}$ Consultant, Nandini Hospital, Davangere, Karnataka, India
\end{abstract}

Received: 21 February 2019

Accepted: 25 February 2019

\author{
*Correspondence: \\ Dr. Sunitha H. B. \\ E-mail: suni.hb140bg@gmail.com
}

Copyright: (c) the author(s), publisher and licensee Medip Academy. This is an open-access article distributed under the terms of the Creative Commons Attribution Non-Commercial License, which permits unrestricted non-commercial use, distribution, and reproduction in any medium, provided the original work is properly cited.

\begin{abstract}
Background: Anemia due to Iron deficiency is the commonest malnutrition disorder seen throughout the world and in India. It is also responsible for increased incidence of premature births, low birth weight babies and high perinatal mortality. Hence, the present study undertaken to assess efficacy and safety of injectable iron sucrose with oral ferrous ascorbate.

Methods: 100 pregnant women, between gestational age 14 and 28 weeks were divided randomly into two groups i.e. group A consists of oral iron, a total of $200 \mathrm{mg}$ of elemental iron per day, two 100mg iron tablets per day and group B consists of iron sucrose at the rate of $200 \mathrm{mg}$ on alternate OPD day. Informed consent was taken from each patient.

Results: The percentage rise in hemoglobin at fourth and eighth weeks of treatment was statistically significant when compared to the baseline. Statistically significant rise in hemoglobin, PCV and ferritin levels were found at fourth and eighth weeks in IV group when compared to oral group.

Conclusions: This study concluded that intravenous iron sucrose is safe and highly efficacious for the treatment of anemia in pregnancy. It restores iron stores more promptly. Iron sucrose therapy is more effective in achieving the optimum results, an increase in hemoglobin concentration, PCV levels and an increase in ferritin levels also. Therefore, it is a suitable alternative to oral iron with minimal side effects in those patients who cannot tolerate oral iron therapy.
\end{abstract}

Keywords: Anaemia, Iron sucrose, Ferrous ascorbate, Pregnancy

\section{INTRODUCTION}

Anaemia is defined as haemoglobin level in the blood is below the lower extreme of the normal range for the age and sex of the individual. The importance of anaemia as a major public health problem throughout the world is widely recognized. ${ }^{1}$ According to $\mathrm{WHO}$, in developing countries the prevalence of anaemia among pregnant women averages $56 \%$, ranging between 35 to $100 \%$ among different regions of the world. Various studies from different regions of the country (India) have reported the prevalence of anaemia to be between 33 and $100 \% .^{1}$ Anemia due to Iron deficiency is the commonest malnutrition disorder seen throughout the world and in India. $^{2}$ The single most important cause for the widespread Iron deficiency anemia in our country is inadequate iron intake in the habitual diets combained with the poor bioavailability of dietary iron. ${ }^{3}$ In India, anaemia is the second most common cause of maternal deaths, accounting for $20 \%$ of total maternal deaths.

Anaemia affects mainly the women in child bearing age group, young children and adolescent girls. ${ }^{4}$ Apart from the risk to the mother, it is also responsible for increased incidence of premature births, low birth weight babies and high perinatal mortality. ${ }^{5}$ 
However, risk factors such as Anemia in pregnancy can be controlled and monitored by good antenatal care and appropriate action, including referral, in accordance to the level of severity of the anemia. ${ }^{5}$ Haemoglobin level at or below $9 \mathrm{gm} / \mathrm{dl}$ requires detailed investigations and appropriate treatment. Considering the above facts, the present study was planned to assess efficacy and safety of injectable iron sucrose with oral ferrous ascorbate. The objectives of the present study was to compare the response of intravenous iron sucrose with that of oral ferrous ascorbate in the treatment of anaemia in pregnancy, and to compare the acceptability, efficacy and side effects of injectable iron over oral ferrous ascorbate in the treatment of anaemia in pregnancy

\section{METHODS}

This randomized trial was conducted in Obstetrics and Gynaecology Department of Kempegowda Institute of Medical Sciences Hospital and Research Centre, Bangalore. All pregnant women, between gestational age 14 and 28 weeks were divided randomly into two groups:

Group A: Consisted of pregnant women, who were given oral iron, a total of

$200 \mathrm{mg}$ of elemental iron per day, two 100mg iron tablets per day was administered.

Group B: Consisted of pregnant women who were given iron sucrose at the rate of $200 \mathrm{mg}$ on alternate OPD day, the dose for total iron sucrose was calculated from the following formula:

Dose of iron $(\mathrm{mg})=0.24 \mathrm{X}$ Haemoglobin deficit $\mathrm{X}$ body weight in $\mathrm{kgs}+5006$

Rounded up to the nearest multiple of $100 \mathrm{mg}$.

In the formula, weight represented the patient's weight before pregnancy in kilograms, target hemoglobin was set at $11 \mathrm{~g} / \mathrm{dl}$.

In each infusion, the maximum total dose administered was $200 \mathrm{mg}$ iron sucrose in $100 \mathrm{ml}$ of $0.9 \% \mathrm{NaCl}$ saline, slow IV infused over 20-30 minutes. No test dose was given. Treatment was completed after administration of the calculated dose. Monitoring was done throughout the infusion to observe for any side effects. 6

Iron-sucrose infusions were administered in outpatient and inpatient setting, and all patients were observed for 1 hour after the infusions. All adverse events after each infusion of elemental iron were identified by physical examination and direct inquiry of each patient, using standard forms encoded for adverse events. Blood pressure was measured before, during, and after each infusion, and hypotension was recorded as an adverse event if it was clinically significant.

\section{Inclusion criteria}

- Normal singleton pregnancy

- No complicating factors

- Gestational age of 14-28 weeks

- Hemoglobin concentration of more than $8 \mathrm{gm} \%$, but not more than $10.5 \mathrm{gm} \%$

- Women's consent for inclusion in the study

- $\mathrm{MCV}<50 \mathrm{fl}$ and a ferritin level $<50 \mathrm{microgm} / 1$.

\section{Exclusion criteria}

- Any medical disorder like tuberculosis , diabetes, cirrhosis, hepatitis, HIV.

- Any obstetrical complicating factors like PIH,APH etc.

- Any patient with hemoglobin less than $8 \mathrm{gm} \%$ or more than $10.5 \mathrm{gm} \%$.

- Patients with multiple pregnancy, acute and chronic infections.

- Intolerance to iron derivatives and parenteral iron treatment before inclusion.

\section{Procedure for Leishman's staining}

Air dried film was flooded with Leishman's stain for two minutes. Double the volume of buffer water was added for 10 minutes. The stain was washed off with distilled water after drying, the back of the slide was wiped clean.

\section{Special biochemical procedures done included}

Measurement of Serum Ferritin concentration. Reference range: $15-200 \mathrm{ng} / \mathrm{ml}$.

Indicators of response to iron sucrose therapy:

- Improved look of the patient

- Better appetite

- General feeling of wellbeing

- Hematological improvement

- Rise in hemoglobin values

- Increase in serum ferritin levels

\section{Visit I}

Information, regarding patient's name, address, age, and history of amenorrhoea was obtained and results of general and obstetric examination were noted, maternal weight was noted.

Investigations included estimation of hemoglobin value, serum ferritin level and peripheral smear examination to note the type of anemia. Iron tablets along with folic acid were given to the oral iron group. Deworming done to both the groups. They were advised regarding diet and were asked to take the iron tablet between meals, and not take coffee or tea before and after taking tablets. They were explained about repeating investigations during 
follow-up visits, after 4 weeks and 8 weeks respectively. The iron sucrose group was also administered folic acid along with therapy and were advised to avoid oral iron during iron sucrose therapy and thereafter.

They were advised to report any adverse side effects immediately. They were explained about repeating investigations during follow-up visits, after a period of 4 weeks and 8 weeks respectively.

\section{Visit II}

After a period of 4 weeks, the pregnant women were examined clinically, and maternal weight was noted. Haemoglobin and serum ferritin estimation was done in both groups to note the improvement in values.

The side effects volunteered by the women were noted and they were advised to continue tablets, in the oral iron group. The iron sucrose group were advised to continue folic acid, and to avoid oral iron.

On subsequent visits, general and obstetric examination was done, and maternal weight and adverse side effects were noted.

\section{Visit III}

After a period of 8 weeks, hemoglobin and serum ferritin estimation was done to note the improvement in values. Any adverse side effects were also noted.

The following parameters were noted:

- Hemoglobin levels and serum ferritin values:

- Visit I - Baseline

- Visit II - After 4 weeks

- $\quad$ Visit III - After 8 weeks

- Adverse reaction monitoring

No direct leading questions were asked to elicit side effects. Only those side effects volunteered by the pregnant women, were recorded.

They were asked to report immediately if there were any unpleasant symptoms during iron sucrose therapy or oral iron therapy.

This report included a detailed description of the symptoms, time of onset and duration, whether treatment was discontinued, and corrective measures taken.

\section{Statistical analysis}

Descriptive statistics such as mean, SD and percentage was used to present data. Comparison between two groups was done by using chi-square test for discrete variable and t-test for continuous variable. A p-value less than 0.05 were considered as significant.

\section{RESULTS}

In group A- age of cases were ranging from 18-42 years with mean age of $24.46+4.71$ years whereas in group B age of cases were ranging from 18-35 years with mean age of $24.72+4.338$ years. This was found to be statistically insignificant. No patients from either group discontinued the study (Table 1).

Table 1: Baseline characteristics of pregnant women.

\begin{tabular}{|c|c|c|}
\hline Characteristics & IV group & Oral group \\
\hline \multicolumn{3}{|l|}{ Age (in years) } \\
\hline $15-20$ & $9(18 \%)$ & $8(16 \%)$ \\
\hline $21-25$ & $25(50 \%)$ & $23(46 \%)$ \\
\hline $26-30$ & $10(20 \%)$ & $13(26 \%)$ \\
\hline $31-35$ & $4(8 \%)$ & $6(12 \%)$ \\
\hline$>35$ & $2(4 \%)$ & 0 \\
\hline \multicolumn{3}{|l|}{ Booking status } \\
\hline Booked & $43(86 \%)$ & $41(82 \%)$ \\
\hline Booked outside & $4(8 \%)$ & $5(10 \%)$ \\
\hline Unbooked & $3(6 \%)$ & $4(8 \%)$ \\
\hline \multicolumn{3}{|l|}{ Gravidity } \\
\hline G1 & $23(46 \%)$ & $19(38 \%)$ \\
\hline $\mathrm{G} 2$ & $13(26 \%)$ & $14(28 \%)$ \\
\hline$>\mathrm{G} 3$ & $14(28 \%)$ & $17(34 \%)$ \\
\hline \multicolumn{3}{|l|}{ GA (weeks) } \\
\hline $14-20$ & $14(28 \%)$ & $17(34 \%)$ \\
\hline $20.1-24$ & $13(26 \%)$ & $12(24 \%)$ \\
\hline $24.1-28$ & $23(46 \%)$ & $21(42 \%)$ \\
\hline \multicolumn{3}{|l|}{ Peripheral smear } \\
\hline Dimorphic & $6(12 \%)$ & $6(12 \%)$ \\
\hline Microcytic hypochromic & $35(70 \%)$ & $36(72 \%)$ \\
\hline $\begin{array}{l}\text { Normocytic } \\
\text { normochromic }\end{array}$ & $9(18 \%)$ & $8(16 \%)$ \\
\hline \multicolumn{3}{|l|}{ Haemoglobin (gm\%) } \\
\hline $8.1-9$ & $34(68 \%)$ & $33(66 \%)$ \\
\hline $9.1-10$ & $16(32 \%)$ & $15(30 \%)$ \\
\hline$>10$ & 0 & $2(4 \%)$ \\
\hline \multicolumn{3}{|l|}{$\operatorname{PCV}(\%)$} \\
\hline $20.1-25$ & $12(24 \%)$ & $11(22 \%)$ \\
\hline $25.1-30$ & $34(68 \%)$ & $31(62 \%)$ \\
\hline$>30.1$ & $4(8 \%)$ & $8(16 \%)$ \\
\hline \multicolumn{3}{|l|}{ S. Ferritin (micgm/l) } \\
\hline$\leq 20$ & $34(68 \%)$ & $30(60 \%)$ \\
\hline $21-40$ & $16(32 \%)$ & $18(36 \%)$ \\
\hline$\geq 41$ & 0 & $2(4 \%)$ \\
\hline
\end{tabular}

Among the 100 women studied $82-86 \%$ were booked, 8$10 \%$ were booked outside and remaining 6-8\% were unbooked, which was found to be statistically insignificant between the groups $(p>0.05)$. Among the studied patients, in IV group $46 \%$ were G1, 26\% were G2 and remaining $28 \%$ were $>\mathrm{G} 3$. In oral group, $38 \%$ were $\mathrm{G} 1,28 \%$ were $\mathrm{G} 2$ and remaining $34 \%$ were $>\mathrm{G} 3$.

The range of gestational age at the time of inclusion in the study was 14-28 weeks. In group A, mean gestational age 23.04+4.14weeks and in group B mean gestational 
age $22.48+4.21$ weeks. This was found to be statistically insignificant $\quad(\mathrm{p}>0.05)$. 70-72\% were microcytic hypochromic, 16-18\% were Normocytic normochromic and remaining patients showed dimorphic smear, which was found to be statistically insignificant between the groups ( $p>0.05)$. The baseline hemoglobin was in the range of 8 to $10.5 \mathrm{~g} / \mathrm{dl}$. Maximum number of patients from both groups had hemoglobin levels between 8.1 to 9 $\mathrm{g} / \mathrm{dl}$. The mean baseline hemoglobin was 8.52 and $8.73 \mathrm{~g} / \mathrm{dl}$ in IV group and oral group respectively, which was found to be statistically insignificant between the groups ( $p>0.05$ ). Maximum number of patients from both groups had PCV levels between 25.1 to $30 \%$. The mean baseline PCV was 26.64 and 26.81 in IV group and oral group respectively, which was found to be statistically insignificant between the groups $(p>0.05)$.

Maximum number of patients from both groups had Ferritin levels of $<20$ microg/l. The mean baseline Ferritin was 18.25 and 17.89 microg/l in IV group and oral group respectively, which was found to be statistically insignificant between the groups $(\mathrm{p}>0.05)$.

Table 2: Adverse reactions.

\begin{tabular}{|l|l|l|}
\hline Adverse reactions & IV group & Oral group \\
\hline Nausea/vomiting & 1 & 2 \\
\hline Epigastric pain & 1 & 2 \\
\hline Constipation & 0 & 1 \\
\hline Staining & 1 & 0 \\
\hline Total & 3 & 5 \\
\hline
\end{tabular}

There were no serious adverse effects in the study. However, 3 pregnant women out of 50 in IV group and 5 out of 50 pregnant women in oral group had minimal side effects, they continued with the study. This was statistically significant (Table 2). All of the patients in the IV group were received the calculated total iron dose. The median dose administered was $600-700 \mathrm{mg}$ i.e. 6-7 ampoules of $100 \mathrm{mg}$ (Iron sucrose requirement range between $600-1000 \mathrm{mg}$ ) of elemental intravenous iron. The mean haemoglobin concentration at the first visit i.e. baseline haemoglobin and the rise in haemoglobin values in the subsequent visits.

Table 3: Comparison of haemoglobin percentage during different visits in both groups.

\begin{tabular}{|l|l|l|l|}
\hline \multirow{2}{*}{ Visits } & \multicolumn{2}{|l|}{ Haemoglobin (gm \%) } & \multirow{2}{*}{ P-value } \\
\hline Base line & 8.52 & 8.73 & \\
\hline 4 weeks & 9.72 & 9.64 & \multirow{2}{*}{0.001} \\
\hline 8 weeks & 11.45 & 10.8 & \\
\hline
\end{tabular}

The mean baseline haemoglobin was 8.52 and $8.73 \mathrm{~g} / \mathrm{dl}$ in IV group and oral group respectively. Post treatment haemoglobin after 4 weeks showed a mean value of $9.72 \% \mathrm{gm} / \mathrm{dl}$ and $9.64 \mathrm{gm} / \mathrm{dl}$ respectively $(\mathrm{p}<0.001)$, which was statistically significant. The average rise of haemoglobin was $1.2 \mathrm{gm} / \mathrm{dl}$ and $0.91 \mathrm{gm} / \mathrm{dl}$ respectively $(\mathrm{p}<0.001)$, which was statistically significant (Table 3 ). Post treatment haemoglobin after 8 weeks showed a mean value of $11.45 \% \mathrm{gm} / \mathrm{dl}$ and $10.8 \mathrm{gm} / \mathrm{dl}$ respectively $(\mathrm{p}<0.001)$, which was statistically significant. The average total rise of haemoglobin was $2.93 \mathrm{gm} / \mathrm{dl}$ and $2.07 \mathrm{gm} / \mathrm{dl}$ respectively $(\mathrm{p}<0.001)$, which was statistically significant.

The mean PCV concentration at the first visit i.e. baseline PCV and the rise in PCV values in the subsequent visits. The mean baseline PCV was $26.64 \%$ and $26.81 \%$ in IV group and oral group respectively. Post treatment PCV after 4 weeks showed a mean value of $29.75 \%$ and $29.7 \%$ respectively ( $\mathrm{p}<0.001)$, which was statistically significant. The average rise of PCV was $3.11 \%$ and $2.89 \%$ respectively $(\mathrm{p}<0.001)$, which was statistically significant. Post treatment PCV after 8 weeks showed a mean value of $34.07 \%$ and $32.16 \%$ respectively $(\mathrm{p}<0.001)$, which was statistically significant. The average total rise of PCV was $7.43 \%$ and $5.35 \%$ respectively $(\mathrm{p}<0.001)$, which was statistically significant (Table 4).

Table 4: Comparison of PCV \% during different visits in both groups.

\begin{tabular}{|c|c|c|c|}
\hline \multirow{2}{*}{ Visits } & \multicolumn{2}{|c|}{ PCV (\%) } & \multirow{2}{*}{ P-value } \\
\hline & IV group & Oral group & \\
\hline Base line & 26.64 & 26.81 & \multirow{3}{*}{0.001} \\
\hline 4 weeks & 29.75 & 29.70 & \\
\hline 8 weeks & 34.07 & 32.16 & \\
\hline
\end{tabular}

The mean S. Ferritin concentration at the first visit i.e. baseline S. Ferritin and the rise in S. Ferritin values in the subsequent visits. The mean baseline S. Ferritin was $18.25 \mathrm{microgm} / \mathrm{l}$ and $17.89 \mathrm{microgm} / \mathrm{l}$ in IV group and oral group respectively. Post treatment Ferritin after 4 weeks in IV and oral group showed a mean value of $28.19 \mathrm{microgm} / \mathrm{l}$ and $20.74 \mathrm{microgm} / \mathrm{l}$ respectively (p value $<0.001$ ), which was statistically significant. The average rise of Ferritin was 9.94 microgm/l and 2.85 microgm/l respectively $(\mathrm{p}<0.001)$, which was statistically significant.

Post treatment Ferritin after 8 weeks in IV and oral group showed an mean value of $32.05 \mathrm{microgm} / \mathrm{l}$ and 24.47 microgm/l respectively ( $\mathrm{p}<0.001)$, which was statistically significant. The average total rise of Ferritin was $13.8 \mathrm{microgm} / \mathrm{l}$ and $6.58 \mathrm{microgm} / \mathrm{l}$ in IV and oral group respectively $(\mathrm{p}<0.001)$, which was statistically significant (Table 5).

Table 5: Comparison of ferritin percentage during different visits in both groups.

\begin{tabular}{|c|c|c|c|}
\hline \multirow{2}{*}{ Visits } & \multicolumn{2}{|c|}{ S Ferritin (microgm/l) } & \multirow{2}{*}{ P-value } \\
\hline & IV group & Oral group & \\
\hline Base line & 18.25 & 17.89 & \multirow{3}{*}{0.001} \\
\hline 4 weeks & 28.19 & 20.74 & \\
\hline 8 weeks & 32.05 & 24.47 & \\
\hline
\end{tabular}




\section{DISCUSSION}

Anemia due to Iron deficiency is the commonest malnutrition disorder seen throughout the world and in India, affecting $35-75 \%$ (average 56\%) of pregnant women in developing countries and $18 \%$ of women from industrialized countries are anemic. ${ }^{1}$ Currently there are many oral iron and intravenous preparations available. The traditional treatments, i.e., oral iron therapy and blood transfusion, involve significant drawbacks. High doses of oral iron frequently cause side effects, and noncompliance is common. Administration of oral iron supplementations is not sufficient enough in order to reverse anemia promptly, due to the limited absorption, the gastrointestinal symptoms and the poor compliance for long treatment of the patients. As far as blood transfusions are concerned, because of the risk of infection (bacterial, viral, prions) and immunomodulation associated with allergenic blood products, especially in this young and otherwise healthy population, transfusions are used only in the most severe cases and particularly in life-threatening situations. Therefore, intravenous iron, has been considered as an alternative in the management of iron deficiency anemia.

The characteristics of patients in group A and in group B were statistically comparable in relation to age. In the study majority of women were in the age group of $21-25$ years. Mean age of the patients in other studies were approximately similar to present study. In all the studies maximum number of patients were primigravidas. This is explained by high prevalence of iron deficiency anemia in adult non-pregnant women (In present study group $46 \%$ and $38 \%$ were primigravidas). When these anemic women become pregnant, their anemia will be aggravated by increased need of iron during pregnancy, and it is important to screen iron deficiency anemia in all nonpregnant child bearing age group women as recommended by Centre of Disease Control and Prevention (CDC).

In the present study the mean of gestational age at the time of inclusion in both the groups was comparable (in group A 23.04+4.14weeks and in group B 22.48+4.21 weeks). The mean of gestational age in the Ragip et al and Bayoumeu et al were same as that of the present study. ${ }^{7,8}$ In the present study $70-72 \%$ showed microcytic hypochromic blood picture in peripheral smear, 16-18\% were Normocytic normochromic and remaining had a dimorphic smear. Ragip et al and Bayoumeu et al also found similar blood picture as Iron deficiency is the commonest malnutrition disorder present with microcytic hypochromic blood picture., ${ }^{7,8}$ In present study, the baseline hemoglobin was in the range of 8 to $10.5 \mathrm{~g} / \mathrm{dl}$. Maximum number of patients from both groups had hemoglobin levels between 8.1 to $9 \mathrm{~g} / \mathrm{dl}$. The mean baseline hemoglobin was 8.52 and $8.73 \mathrm{~g} / \mathrm{dl}$ in IV group and oral group respectively, which was found to be statistically insignificant between the groups. In the
Ragip et al study, hemoglobin levels between 8 and 10.5 g/dL were taken. ${ }^{7}$

In the Bayoumeu et al, hemoglobin level between 8 and $10 \mathrm{~g} / \mathrm{dL}$ were studied. ${ }^{8}$ Maximum number of patients from both groups had PCV levels between 25.1 to $30 \%$. The mean baseline PCV was $26.64 \%$ and $26.81 \%$ in both groups respectively. In this study majority of the patients from both groups had S. Ferritin levels of <20 microg/l. The mean baseline S. Ferritin was 18.25 and 17.89 microg/l in IV and oral groups respectively. In the Ragip et al and Bayoumeu et al studies, S. Ferritin levels were < 13 microgm $/ 1$ and a S. Ferritin level $<50 \mu \mathrm{g} / \mathrm{L}$ respectively. ${ }^{7,8}$ The mean baseline hemoglobin was 8.52 and $8.73 \mathrm{~g} / \mathrm{dl}$ in IV group and oral group respectively. Post treatment hemoglobin after 4 weeks showed a mean value of $9.72 \% \mathrm{gm} / \mathrm{dl}$ and $9.64 \mathrm{gm} / \mathrm{dl}$ in IV and oral group respectively ( $\mathrm{p}$ value $<0.001$ ), which was statistically significant. The average rise of hemoglobin was $1.2 \mathrm{gm} / \mathrm{dl}$ and $0.91 \mathrm{gm} / \mathrm{dl}$ in IV and oral group respectively ( $\mathrm{p}$ value 0.001 ), which was statistically significant. In the Ragip et al study, average rise of hemoglobin was $1.2 \mathrm{gm} / \mathrm{dl}$ and $0.6 \mathrm{gm} / \mathrm{dl}$ respectively ( $\mathrm{p}$ value 0.001 ), almost similar to present study. In the Bayoumeu et al a clear increase in hemoglobin was observed in the 2 groups, rising from $9.6 \pm 0.79 \mathrm{~g} / \mathrm{dl}$ to $11.11 \pm 1.3 \mathrm{~g} / \mathrm{dl}$ on day 30 in the IV group and from $9.7 \pm 0.5 \mathrm{~g} / \mathrm{dl}$ to $11 \pm 1.25 \mathrm{~g} / \mathrm{dl}$ on day 30 in the PO group. ${ }^{8}$ Post treatment hemoglobin after 8 weeks showed a mean value of $11.45 \% \mathrm{gm} / \mathrm{dl}$ and $10.8 \mathrm{gm} / \mathrm{dl}$ in IV and oral group respectively ( $\mathrm{p}<0.001)$, which was statistically significant. The average total rise of hemoglobin was 2.93 $\mathrm{gm} / \mathrm{dl}$ and $2.07 \mathrm{gm} / \mathrm{dl}$ in IV and oral group respectively (p value 0.001 , which was statistically significant. In the Ragip et al study, average rise of hemoglobin was 2.1 $\mathrm{gm} / \mathrm{dl}$ and $1.5 \mathrm{gm} / \mathrm{dl}$ in IV and oral group respectively $(p<0.001)$, which was statistically significant. ${ }^{7}$ Also present study could be compared to a study by A. Dede, D.Uygut et al at the Zakai Tahi Burak Women's Health Education and Research Hospital, Division of Perinatology, Turkey, which included seventy five $(n=75)$ postnatal women with $\mathrm{Hb}<9 \mathrm{~g} / \mathrm{dl}$ after delivery whether vaginal or caesarean and compared the effect of intravenous iron sucrose complex versus oral ferrous sulphate and compared the results at the end of 28 days. ${ }^{9}$ The mean $\mathrm{Hb} \%$ at the start of treatment was $8.2 \pm 0.6 \mathrm{~g} / \mathrm{dl}$ in both the groups. But the mean raise in $\mathrm{Hb} \%$ at the end of 28 days was $12.5 \pm 1.6 \mathrm{~g} / \mathrm{dl}$ and $11.8 \pm 0.7 \mathrm{~g} / \mathrm{dl}$ in the intravenous and oral group respectively. $\mathrm{P}$ value was 0.200 which was not significant. However, the raise in mean $\mathrm{Hb}$ in the intravenous group was $4.3 \mathrm{~g} / \mathrm{dl}$. The mean baseline PCV was $26.64 \%$ and $26.81 \%$ in in IV and oral group respectively. Post treatment PCV after 4 weeks showed, an average rise of PCV was $3.11 \%$ and $2.89 \%$ in IV and oral group respectively $(\mathrm{p}<0.001)$, which was statistically significant. Post treatment PCV after 8 weeks showed, an average total rise of PCV of $7.43 \%$ and $5.35 \%$ in IV and oral group respectively $(p<0.001)$, which was statistically significant. 
The mean baseline S. Ferritin was $18.25 \mathrm{microgm} / \mathrm{l}$ and $17.89 \mathrm{microgm} / \mathrm{l}$ in IV group and oral group respectively. Post treatment Ferritin after 4 weeks showed an average rise of $9.94 \mathrm{microgm} / \mathrm{l}$ and $2.85 \mathrm{microgm} / \mathrm{l}$ respectively $(\mathrm{p}<0.001)$, which was statistically significant. Post treatment S.Ferritin after 8 weeks showed average total rise of $13.8 \mathrm{microgm} / \mathrm{l}$ and $6.58 \mathrm{microgm} / \mathrm{l}$ respectively ( $<<0.001)$, which was statistically significant. In the Ragip et al study, Ferritin values were found to be changed significantly across time within both the oral ( $\mathrm{P}$ $<0.05)$ and intravenous groups $(\mathrm{P}<0.05) 7$. The serum ferritin value was higher in the intravenous iron group than in the oral iron group at each point of measurement. It was $11+11 \mathrm{micrgm} / \mathrm{l}$ compared with $28 \pm 26$ micrgm/l (P $<0.05)$ at the fourth week and $18.1 \pm 11$ micrgm/ compared with $23.7 \pm 13.8 \mathrm{micrgm} / \mathrm{l}(\mathrm{P}<0.05)$ at 8 weeks in the oral and intravenous iron groups, respectively. In the Bayoumeu et al, at end of fourth week, there was a highly significant difference in ferritin levels between the 2 groups with iron reserves restored only in the IV group $(\mathrm{P}<0.0001) .{ }^{8}$ There were no serious adverse effects in the study, however $3(6 \%)$ in IV group and $5(10 \%)$ in oral group had minimal side effects but continued with the study. Same observations reported in other studies like Al-Momen et al10, Bayoumeu et al and Ragip et al without serious adverse effects. ${ }^{7,8}$ In another study, it was reported that, the change in hemoglobin and ferritin levels from baseline was significantly higher in the intravenous group than the oral group at each measurement $(\mathrm{P}=0.000){ }^{11}$ Similar findings were observed in the present study. Compliance in the study was, for the most part, fairly high. There were no drop outs from the study and in the clinical setting it may be difficult to get the same rate of compliance for oral iron therapy. Majority of the patients in the IV group received the calculated total iron dose. The median dose administered was $600-700 \mathrm{mg}$ i.e. 6-7 ampoules of $100 \mathrm{mg}$ of intravenous Iron sucrose.

\section{CONCLUSION}

This study concluded that intravenous iron sucrose is safe and highly efficacious for the treatment of anemia in pregnancy. It restores iron stores more promptly. Iron sucrose therapy is more effective in achieving the optimum results, an increase in hemoglobin concentration, PCV levels and an increase in ferritin levels also. Therefore, it is a suitable alternative to oral iron with minimal side effects in those patients who cannot tolerate oral iron therapy.

Funding: No funding sources Conflict of interest: None declared

Ethical approval: The study was approved by the Institutional Ethics Committee

\section{REFERENCES}

1. World Health Organization. Nutritional anaemias: report of a WHO scientific group [meeting held in Geneva from 13 to 17 March 1967].

2. WHO U. UNU. Iron deficiency anaemia: assessment, prevention, and control. Geneva, WHO. 2001.

3. WHO, The prevalence of anemia in women: A tabulation of available information, WHO/MCH/MSM/92.2 World Health Organization, 1992.

4. Centers for Disease Control and Prevention. Recommendations to prevent and control iron deficiency in the United States. MMWR Recomm Rep. 1998;47(RR-3):1-29.

5. Vijayaraghavan K, Brahmam GN, Nair KM, Akbar $\mathrm{D}$, Rao NP. Indian council of medical research. Task force study Evaluation of national nutritional anemia prophylaxis programme. Indian $\mathrm{J}$ Pediatr. 1990;57(2):183-90.

6. Singh K, Fong YF, Kuperan P. A comparison between intravenous iron polymaltose complex (Ferrum Hausmann) and oral ferrous fumarate in the treatment of iron deficiency anemia in pregnancy. Eur J Haematol. 1998;60(2):119-24.

7. Ragip A, Intravenous versus oral iron for treatment of anemia in pregnancy, A randomized trial, ACOG. 2005;106(6):1335-40.

8. Bayoumeu F, Subiran-Buisset C, Baka NE, Legagneur H, Monnier-Barbarino P, Laxenaire MC. Iron therapy in iron deficiency anemia in pregnancy: intravenous route versus oral route. European Journal of Obstet Gynecol Reproduct Biol. 2005;123:S15-9.

9. Dede A, Uygur D, Yilmaz B, Mungan T, Uğur M. Intravenous iron sucrose complex vs. oral ferrous sulfate for postpartum iron deficiency anemia. Int $\mathbf{J}$ Gynecol Obstet. 2005;90(3):238-9.

10. Al-Momen AK, Al-Meshari A, Al-Nuaim L, Saddique A, Abotalib Z, Khashogji T, Abbas M. Intravenous iron sucrose complex in the treatment of iron deficiency anemia during pregnancy. European Journal of Obstet Gynecol Reproduct Biol. 1996;69(2):121-4.

11. Shafi D, Purandare SV, Sathe AV. Iron deficiency anemia in pregnancy: intravenous versus oral route. $\mathrm{J}$ Obstet Gynecol India. 2012;62(3):317-21.

Cite this article as: Sunitha HB, Kumar SG.

Comparison of efficacy and safety of injectable iron sucrose with oral ferrous ascorbate in the treatment of anaemia in pregnancy. Int $\mathrm{J}$ Reprod Contracept Obstet Gynecol 2019;8:1277-82. 